\author{
$\underline{\text { Auteurs }}$ \\ Claude Diebolt, Faustine Perrin \\ Document de Travail $n^{\circ} 2017-03$
}

Faculté des sciences économiques et de gestion

61 avenue de la Forêt Noire F-67085 Strasbourg Cedex

Secrétariat du BETA

Géraldine Del Fabbro Tél. : (33) 0368852069 Fax : (33) 0368852070 g.delfabbro@unistra.fr www.beta-umr7522.fr 


\title{
A Cliometric Model of Unified Growth Family Organization and Economic Growth in the Long Run of History
}

\author{
Claude DIEBOLT and Faustine PERRIN*
}

\begin{abstract}
This chapter explores the role of gender equality over the long-run economic and demographic development path of industrialized countries. It accounts for changes in fertility, technology, and income per capita in the transition from stagnation to sustained growth. Our unified cliometric growth model of female empowerment suggests that changes in gender relations, triggered by endogenous skill-biased technological progress, induce women to invest in skilled education and engage a process of buman capital accumulation. In parallel, a bigher time spent by women in education increases the opportunity cost of having children and reduces fertility. This positive feedback loop generates both a demographic and an economic transition.
\end{abstract}

Keywords: Cliometrics, Economic Growth, Gender, Fertility, Human Capital

JEL Classification: J1, N3, O4

* Diebolt: Department of Economics, BETA/CNRS (UMR 7522), University of Strasbourg, 61 avenue de la Forêt Noire, France (e-mail: cdiebolt@unistra.fr); Perrin: Department of Economic History, Lund University, Box 7083, SE22007 Lund, Sweden (e-mail: faustine.perrin@ekh.lu.se). 


\section{Introduction}

The relationship between gender equality and long-run economic growth has received little attention from theorists so far. Understanding gender roles is difficult in that it requires a global understanding of family organization and its interaction with the marketplace. However, we strongly believe that changes in gender roles have played a key role in the economic development of modern societies. Insights from economics suggest the role of women to be a strategic variable in economic development, through its effects on demographic behavior and human-capital formation in the next generation.

During the past two centuries, the Western world witnessed dramatic economic, demographic and cultural upheavals. This period marks a turning point in historical economic and demographic trends. Western countries experienced similar patterns of economic and demographic transition, despite some variations in terms and timing and speed of changes (Galor, 2012). Before the Industrial Revolution, all societies were characterized by a very long period of stagnation in per capita income with high fertility rates. Since this fateful period, Western countries observed a complete reversal with high sustained income per capita and low fertility (Becker et al., 2012, Klemp, 2012). In parallel to economic and demographic transitions, we note profound changes in the structure of the population: formal education became accessible to a vast majority of the population while drastic changes occurred in gender relations.

Empirical regularities raise numerous questions about the potential interaction between female empowerment, demographic transition and economic development; and about its role in the transition from the epoch of Malthusian stagnation to the Modern Growth Regime. What can explain the dramatic reversal of the relationship between output growth and population? What are the underlying behavioral forces behind the demographic transition? What are the endogenous interactions between education and fertility that result in the transition phase? Could female empowerment account for the observed take-off from stagnation to sustained growth in Western countries?

This chapter contributes to the literature on unified growth theory by bringing to light new determinants of the long transition process. Our model incorporates novel and additional mechanisms consistent with observed stylized facts, emphasizing the importance of the role played by women and family organization in the development process. Rare are growth models that differentiate the role of men and women in their analysis, considering rather the effect of household 
decisions on fertility. We choose here to tackle the issue of the development process by a renewed gendered approach. The main concern of the chapter is precisely to show to what extent and through which mechanisms gender equality affects decisions taken by members of the household and acts on long-run economic development. We examine mechanisms that are likely to have played an important role in the sequence of events leading to the transition from high birth and death rates to low birth and death rates as countries developed from a pre-industrial to an industrialized economic system. In particular, we explore how the transition from a "Patriarchal" organization of the society (male-breadwinner model) - characterized by a sexual division of labor with a desire for households to maximize both their income and the number of children - toward a "Modern" organization of the society (dual-earnings model) - characterized by a better distribution of duties within the household, where both men and women work on the labor market - may have contributed to the process of development that occurred in Western countries.

We develop a unified cliometric growth model that captures the interplay between fertility, technology, and income per capita in the transition from stagnation to sustained growth. The theory suggests that female empowerment has been at the origin of the demographic transition and engaged the take-off to Modern economic growth. In line with empirical evidence, the theory characterizes the conditions under which the process of human capital accumulation initiated. Changes in the shares of population acquiring skilled human capital have substantial effects on fertility patterns and affect individuals' living conditions. In particular, we consider a two-sex overlapping-generations framework with two types of human capital and integrating aspects of gender relations/equality. Households' members receive utility from their own consumption and from the potential lifetime income of their children. Therefore, they decide about the amount of time to invest in the education process and the number of children they want to raise. We consider all childrearing completely done by women. The key state variables for individuals' decisions are the technological environment and the power-imbalance ratio between sexes. A rapid change in technological environment increases the return to skilled education and increases both boys' education and fertility through an income effect. Higher gender equality (triggered by the acceleration of the pace of technological progress) increases girls' education and reduces the total number of children, through a substitution effect. Furthermore, given the assumption that all childrearing is done by women, maternal endowment in human capital is recognized as being primordial in the educative development of children. Ultimately, higher gender equality changes the trade-off from quantity of children toward quality of children. The average level of fertility therefore depends on the skill composition of the population. 
The different elements of our model lead to a positive feedback loop. At the dynamic level, the increase in gender equality and the rise in technological progress create higher opportunities for women to invest in skilled human capital. The negative correlation linking maternal investments in human capital and fertility encourages families to have fewer children but better educated ones. Dynamically, it affects the incentive for individuals to acquire skilled human capital. Human capital being a factor with increasing returns to scale, the reallocation of resources toward this factor sets the economy on a growing path dependency.

The chapter proceeds as follows. Section 1 briefly reviews the related literature. Section 2 develops the model. Section 3 investigates the dynamic evolution of the economy. Finally, section 4 summarizes and concludes the chapter.

\section{Related Literature}

Women related issues have become central to the field of labor economics and economic history (Goldin, 2006); nevertheless it remains rare in the field of economic growth. If the empirical literature on the link between gender equality and economic development is rather abundant (Schultz, 1995; Klasen, 2002; Knowles et al., 2002, among many others), theoretical literature remains scarce. Galor and Weil (1996), Lagerlöf (2003), Soares and Falcao (2008), Doepke and Tertilt (2009), or more recently de La Croix and Vander Donckt (2010), are part of the few theorists having integrated gender differentiation in their model. ${ }^{1}$

Theories which aim to explain economic growth and development have for a long time been inspired by Malthusian and Neoclassical conceptions.

Despite the capacity of the Malthusian theory to capture the characteristics of the epoch of stagnation, its predictions appear inconsistent with the features of the post-demographic transition era as well as with that of the modern growth regime. Exogenous growth models, such as Solow's model (1956), deal with demographic growth but as an exogenous variable, assuming demographic behaviors independent of wages, incomes, and prices. The lack of consideration of family behavior and its impacts led to the creation of a new stream of research: the "New Home Economics" (initiated by Becker and Mincer in the 1960s). The New Home Economics extended the domain of microeconomic analysis to a wide range of behavior and human interaction, such as demographic

1 See Cuberes and Teignier-Baquet (2012) for a review of the empirical and theoretical literature on gender equality and economic growth. 
behavior, investments in human capital, intergenerational transfers, and including the distribution of work and allocation of time in the family. ${ }^{2}$ A decade later, Nerlove (1970), Razin and Ben-Zion (1975), or Srinivasan (1988) linked demographic behaviors to macroeconomic evolutions in order to analyze their implications on the general equilibrium. ${ }^{3}$ Inspirited by these papers and by the endogenous growth models of Romer $(1986,1990)$ and Lucas (1988), growth models with explicit microeconomic foundations of family have then progressively been developed (see for instance Barro and Becker, 1989; Becker, Murphy and Tamura, 1990; Ehrlich and Lui, 1991; Galor and Weil, 1996; Dahan and Tsiddon, 1998; Iyigun, 2000).

Theorists have examined a set of plausible explanations being at the root of the demographic transition and the reversal in the relation between income and population growth. Among these potential factors is the decline in child mortality rates, leading to a corresponding decrease in total fertility rates. Some researchers (such as Becker, 1981) also argue that the rise in per capita income had an effect on both the household's income and the opportunity cost of raising children. In both cases, historical (and empirical) evidences contradict these potentialities. First, in Western countries the decline in mortality started a century before the decline in fertility. Secondly, the demographic transition occurs simultaneously across countries that significantly differ in their income per capita.

The gradual rise in the demand for human capital along the process of industrialization was then suggested as a prime force leading to the onset of the demographic transition, specifically during the second phase of the Industrial Revolution. Taking family as a single decision-maker, Becker's models manage to generate a demographic transition. Becker et al. (1990), for instance, model the relationship between human capital, fertility and economic growth. In this "one sex" model with altruistic parents, higher productivity leads to higher wages and favors human capital accumulation which in turn raises the opportunity cost of children. This feature highlights the existence of two locally stable steady-states: a Malthusian steady-state with many children and little human capital and a steady-state with few children and high human capital (same result in Tamura, 1994). In the interpretation of the model, they consider changes in female labor force as implicit.

The decline in the gender gap is another argument advanced as a reinforcing mechanism impacting fertility rates. Galor and Weil (1996) investigate the relationship between fertility, gender gap in wages and economic growth by assuming explicitly that men and women have different abilities and do different kinds of work. According to Galor and Weil, technological progress and capital

\footnotetext{
2 Among the first publications are Becker (1960), Mincer (1962), and Becker (1965).

3 Within the framework of neoclassical growth model with endogenous fertility, the authors attempt to determine the optimal population growth rate.
} 
accumulation positively impact the relative wages of women along the process of industrialization what increases the opportunity cost of raising children, and ultimately leads to a reduction in fertility. In a dynamic model with endogenous fertility, Iyigun and Walsh $(2007)^{4}$ explain the decline in fertility through the evolution of the spousal bargaining power within the couples' decision-making problem. Similarly, de la Croix and Vander Donckt (2010) employ the notion of intra-household bargaining power (called "welfare weight") and analyze how its variations may affect demographic and economic outcomes.

The progress of neoclassical growth models with endogenous fertility provide plausible explanations of the modern experience of economic growth in developed economies. Nonetheless, they do not provide a global understanding of the development process as a whole and mysteries persist about some of the most fundamental features of the process of development. This led growth theorists, such as Galor, ${ }^{5}$ to point out the importance of a theory that could captures in a single framework the transition from Malthusian stagnation to sustained economic growth, as well as the associated phenomenon of great divergence and demographic transition.

Galor and Weil $(1999,2000)$ develop the idea that the acceleration in the rate of technological progress gradually increases the demand for human capital, inducing parents to invest in the quality of their offspring rather than in the quantity. Ultimately, the process of human capital accumulation induces a reduction in fertility rates as far as the growth rate of technological progress increases, what leads to a demographic transition, and sustained growth. The model therefore generates a transition from the Malthusian stagnation to the Modern growth regime. Later on, models incorporating new mechanisms emerge. Galor and Moav (2002) and Lagerlöf (2003) share similar intuitions, by suggesting the existence of innate/inherited preferences in terms of children quality. Based on a unitary approach of the family, Lagerlöf (2003) explains how high-quality preferences may have spread over time and generate higher prosperity and lower fertility (considering the evolution of gender discrimination in education but without explaining it). Cervellati and Sunde (2005) introduce complementary mechanisms/channels based on the relations linking life expectancy, human capital and technological progress. Common to all these models (and to ours) is the central role played by the quantity-quality substitution in the transitional phase. As a complement to the existing literature, we integrate a gender dimension to the unified growth framework in order to account for the evolution of gender relations over time.

\footnotetext{
${ }^{4}$ In this chapter, the authors do not focus on economic development and leave aside the question of how changes in gender heterogeneity may affect long-run growth.

${ }^{5}$ See notably Galor $(2005,2011)$.
} 


\section{The Model}

We consider an overlapping-generations model in which the activity extends over infinite continuous time, denoted by $T \in \mathbb{R}^{+}$. The economy is made up of a discrete number of overlapping generations. In every period, the economy produces a single homogenous good, using efficiency units of labor.

Each generation is populated by two kinds of individuals: males $(m)$ and females $(f) .{ }^{6}$ Each males and females are endowed with one unit of time that they split up between market work, education, having and rearing children. In the first period of life, individuals only consume a fraction of parental time endowment. We assume that the time cost of childbearing is greater for women, ${ }^{7}$ so that $\tau^{f} \equiv \tau>\tau^{m}=0$ (as in Iyigun and Walsh, 2007), with $\tau$ the cost of rearing one child. In the second period of life, agents match (randomly) into couples with someone of the opposite sex belonging to the same generation. All adult-members of the households make decisions regarding their own education, ${ }^{8}$ work and fertility. Each household is therefore composed of several individuals: a man and a woman, with different preferences; and their children. Men and women of generation $t$ face a deterministic level of gender equality $\theta_{t}$.

\subsection{Production}

\subsubsection{Production of Final Output}

The production occurs according to a constant-return-to-scale technology that is subject to endogenous technological progress. The unique consumption good (output) is produced using two factors of production: skilled labor $\left(L^{S}\right)^{9}$ and unskilled labor $\left(L^{u}\right)$. The aggregate production function at time $t, Y_{t}$, is given by the following CES production function:

$$
Y_{t}=A_{t} Y\left(L^{u}, L^{S}\right)=A_{t}\left[\left(1-\alpha_{t}\right) L_{t}^{u \rho}+\alpha_{t} L_{t}^{s}\right]^{\frac{1}{\rho}}
$$

\footnotetext{
${ }^{6}$ Males and females have the same abilities and preferences (contrary to Galor and Weil, 1996) but differ in terms of time cost of childbearing.

${ }^{7}$ A recent study of the Observatoire des inégalités (using the Insee "Emploi du temps 2009-2010" survey) shows that women still spend twice more time than men taking care and rearing children.

${ }^{8}$ Contray to most papers with quantity-quality trade-off, in which education is a decision taken by parents (see for example Galor and Moav, 2002 or Lagerlöf, 2003), we consider that educational investments are those of individuals themselves (as in Cervellati and Sunde, 2005).

${ }^{9}$ Skilled labor constitutes adult workers who have invested a fraction of time in schooling when young.
} 
where $\alpha_{t} \in(0,1)$ is the relative productivity share, $A>0$ represents the endogenously determined technological level at time $t$ (total factor productivity) and $\rho \in(0,1)$. All factors of production are assumed to earn their marginal products. The returns from each type of labor at time $t$, respectively unskilled labor, $w_{t}^{u}$, and skilled labor, $w_{t}^{s}$, are:

$$
\begin{aligned}
& w_{t}^{u}=\frac{\partial Y_{t}}{\partial L_{t}^{u}}=A_{t}\left(1-\alpha_{t}\right) L_{t}^{u \rho-1}\left[\alpha_{t} L_{t}^{s \rho}+\left(1-\alpha_{t}\right) L_{t}^{u \rho}\right]^{(1-\rho) / \rho}, \\
& w_{t}^{S}=\frac{\partial Y_{t}}{\partial L_{t}^{s}}=A_{t}\left(\alpha_{t}\right) L_{t}^{s \rho-1}\left[\alpha_{t} L_{t}^{s \rho}+\left(1-\alpha_{t}\right) L_{t}^{u \rho}\right]^{1-\rho} / \rho
\end{aligned}
$$

\subsubsection{The Production of Human Capital}

Human capital can be defined as the stock of (accumulated) knowledge, skills, competencies, attributes embodied in people that improve their ability to perform labor so as to produce economic value. The benefit from embodying additional knowledge in a person may depend positively on the knowledge he or she already has (Becker, Murphy and Tamura, 1990). In order to earn an income $y_{t}^{i}$ and to consume, individuals have to acquire human capital and supplied this human capital to the labor market. The acquisition of human capital requires time. We model the production of human capital as the outcome of an education process involving decisions of parental (maternal) investments in education and of individuals themselves in their own education.

At birth, every individual is endowed with a certain amount of incorporated form of cultural capital, $h_{t-1} \in[0,1]$. This cultural capital is characterized by a set of intellectual qualifications resulting from family environment, and more specifically from parental endowment in human capital. Human capital can be accumulated over time through the education process (that is the institutionalized form of human capital). The effect of parental human capital is reflected by the higher productivity of the share of time unit spent by children in education. The amount of human capital acquired throughout the education process depends therefore on parental endowment in human capital. The larger the human capital embodied in parents $\left(h_{t-1}^{i}\right)$, the larger the effectiveness of the education process, and the larger the impact on resulting human capital $\left(h_{t}^{i}\right)$.

We assume that the time cost of childbearing is greater for women so that $\tau^{f} \equiv \tau>\tau^{m}=0$, with $\tau$ the cost of rearing one child. Therefore, it results that the human capital of each child depends on 
the incorporated form of human capital of its mother (maternal endowment in human capital) rather than of its father.

We denote $e_{t}^{i}$ the amount of time invested by an individual in own education in either type of human capital, $i=u, s$, unskilled or skilled. ${ }^{10}$ The education process differs between these two types of human capital with respect to the time intensity of the education process. There exists a fix cost $\underline{e}$ (in terms of time units) that agents need to pay when acquiring human capital. ${ }^{11}$ The acquisition of skilled human capital involves a larger fix cost of education than the acquisition of unskilled human capital, $\underline{e}^{s}>\underline{e}^{u}$. As a consequence, the number of year spent working is also lower for a skilled individual. We assume that cultural capital (maternal endowment in human capital) is more important when acquiring advanced skills. For simplicity, we assume that $h_{t-1}^{f, s}=h$ and $h_{t-1}^{f, u}=1$.

The human capital production function can be written as follows:

$$
h_{t}^{i}=\beta^{i}\left(e_{t}^{i}-\underline{e}^{i}\right)\left[h_{t-1}^{f, i}\right]
$$

with $\forall e \geq \underline{e}^{i} ; i=u, s$ and $\beta$, the productivity of a unit of education.

An individual that have received an inherited human capital of type $i$ and acquired human capital by investing $e_{t}^{i}$ in education of type $i$ can earn the lifetime income $y_{t}^{i}(h)$, such that:

$$
y_{t}^{i} \equiv y_{t}^{i}\left(h, e_{t}^{i}\right)=w_{t} h_{t}^{i}\left(h, e_{t}^{i}\right)\left[1-e_{t}^{i}\right]
$$

The lifetime income results from supplying human capital on the labor market, itself function of maternal human capital. A World Development Report already emphasized in 1993 the importance of women's income on children welfare. The report highlights a stronger effect of the income of mothers on the welfare of children than does an increase in the husbands' income. The concept of human capital (quality) in addition to abilities, competencies or knowledge embodied in individuals also includes health. Educational investment is a source of labor productivity that positively impact wages. Through this channel, it is very likely that women education also have a stronger effect on children's health than do men education (see Currie and Moretti, 2003).

\footnotetext{
${ }^{10}$ Galor and Moav (2002) already introduced two types of individuals: a quality type, $a$, and a quantity type, $b$, of adult individuals, as a determinant of offspring's quality.

11 Such as in Cervellati and Sunde (2007).
} 


\subsubsection{Technological Progress}

The technology evolves endogenously. Technological progress is assumed to raise the value of education in the production of human capital. ${ }^{12}$ According to Lucas (1988) and Romer (1990), human capital accumulation is an engine of growth. It occurs through the acquisition of education and training which increases the skills and the productivity of the labor force (and promotes the adoption of new ideas and technologies). This implies that technological progress is biased toward high-skill intensive production and depends on the stock of human capital available in the economy. The arrival of new technologies involves larger factor productivity.

$$
g_{t}=\frac{A_{t}-A_{t-1}}{A_{t-1}}=F\left(\Lambda_{t-1}, A_{t-1}\right)
$$

The more individuals of a generation invest in skilled education, the more effective is the accumulation of skilled human capital for future generations.

\subsection{Individuals}

The members of generation $t$ lives for two periods: childhood and adulthood. In the first period of life, individuals are children. They consume a fraction of the parental time endowment. We assume that individuals make no decisions during childhood but they receive parental education. In the second period of life (adulthood), individuals make decisions regarding their own education and fertility (time invested in having and rearing children). The remaining period of time is spent on the labor market (either as skilled or unskilled worker).

As already stated previously, agents of both genders are assumed to be identical except in their time constraint, in that only women endorse the time cost of childbearing. In the model, women decide endogenously what portion of their lifetime to devote to child rearing. Throughout their strategies of life, females choose the optimal mixture of quantity and quality of children ${ }^{13}$ and allocate the rest of their time working on the labor market and consuming their wage. The number of efficiency units of labor is therefore determined by individuals regarding their level of human capital, and number of children.

\footnotetext{
12 Technological progress reduces the adaptability of existing human capital for the new technological environment. Education lessens the adverse effect of technological progress.

13 We will talk here about fertility as quantity and human capital as quality.
} 


\subsubsection{Preferences and Budget Constraint}

Multi-person Dimension Household. - We assume that all individuals get married in the second period of life. The utility function captures the two-sex dimension of the household. Individuals care about their own consumption and about the potential lifetime income of their children. ${ }^{14}$ Household preferences are represented by the following weighted utility function, which is monotonically increasing, concave and satisfies the standard boundary conditions insuring interior solutions,

$$
U\left(c_{t}^{m}, c_{t}^{f}, y_{t+1} n_{t}^{i}\right)=\left(1-\theta_{t}\right) \ln c_{t}^{m}+\theta_{t} \ln c_{t}^{f}+\gamma \ln \left(z_{t+1}^{i} n_{t}^{i}\right)
$$

where $c_{t}^{f}$ and $c_{t}^{m}$ represent respectively the consumption level of the female (wife) and of the male (husband), $n_{t}^{i}$ is the total number of children of the couple, $z_{t+1}^{i}$ denotes the lifetime income of children, ${ }^{15} \gamma \in(0,1)$ measures the value attached to the number of offspring relative to the laborforce participation and $\theta_{t}$ represents the female bargaining power within the household decision process.

The bargaining power of the wife in the household decision process is endogenous and assumed to be a function of human capital stock of the spouses. It shows how human capital affects the bargaining power of the female in the decision process. This parameter can be interpreted as a measure of gender equality within the household and is given by:

$$
\theta_{t}=\frac{w_{t}^{f} h_{t}^{f}}{w_{t}^{f} h_{t}^{f}+w_{t}^{m} h_{t}^{m}} \equiv \varphi\left(h_{t}^{f}, h_{t}^{m}\right)
$$

with $h_{t}^{f}$ and $h_{t}^{m}$, respectively, the female and male endowment in human capital. $\theta_{t} \in(0,1), \theta_{t}=0$ implies total decision-making power for the husband within the household, $\theta_{t}=1$ total power for the wife and $\theta_{t}=0$ characterizes a perfect equality within the couple (the perfect equality between spouses is reflected by $\theta_{t}=1 / 2$ ).

Budget Constraint. - Individuals consume according to the time spent on the market. For women, investment in own education and raising children represent costs in terms of time, time which is not available for market work. Let $\tau n_{t}^{i}+e_{t}^{f, i}$ be the time cost for a female member of generation $t$ of

14 The utility function reflects the trade-off between the resources devoted to own consumption and to raise children.

15 This generates a link between generations (altruistic preferences). 
raising a children, getting a level of education $e_{t}^{i}$ of type $i$. Thereby, the time spent by women on the labor market is what remains after investing in education and raising children. Men only face a cost of time in terms of education. The time spent by men on the labor market is what remains after getting educated. Let $e_{t}^{m, i}$ be the time cost for a male member of generation $t$ of getting a level of education $e_{t}^{i}$ of type $i$. The potential income of men and women is allocated to the consumption, respectively $c_{t}^{m}$ and $c_{t}^{f}$. Wife and husband jointly face the following budget constraint, integrating individual time constraints:

$$
c_{t}^{m}+c_{t}^{f} \leq\left(1-\tau n_{t}^{i}-e_{t}^{f, i}\right) w_{t}^{f, i} h_{t}^{f, i}(\cdot)+\left(1-e_{t}^{m, i}\right) w_{t}^{m, i} h_{t}^{m, i}(\cdot)
$$

Similarly to Becker (1960), Barro and Becker (1989) and Galor and Weil (2000), our model integrates quantity-quality considerations as the household chooses the number of children and their quality, regarding the constraint on the total amount of time individuals can devote to raise children and to work on the labor market. However, unlike existing models, the trade-off relies here on females' decisions making in the face of the trade-off between fertility and own investment in education.

\subsubsection{The Household Choice Problem}

Optimization Problem. - Members of a household of generation $t$ have to choose the type of human capital (through educational investments) they want to acquire, the number of offspring and their own consumption. In period $t$, the household solves the following optimization program:

$$
\left\{e_{t}^{f i *}, e_{t}^{m i *}, n_{t}^{i *}, c_{t}^{f *}, c_{t}^{m *}\right\}=\operatorname{argmax} U_{t}\left(c_{t}^{f *}, c_{t}^{m *}, y_{t+1}^{i} n_{t}^{i}\right)
$$

subject to:

$$
c_{t}^{m}+c_{t}^{f} \leq\left(1-\tau n_{t}^{i}-e_{t}^{f, i}\right) w_{t}^{f, i} h_{t}^{f, i}+\left(1-e_{t}^{m, i}\right) w_{t}^{m, i} h_{t}^{m, i}
$$

(4) and (5) for $i=u, s$

We derive the optimal choice and we get the following set of first order conditions with respect to the spousal consumption levels, optimal fertility and optimal investment in education, conditional to the acquisition of a particular type of human capital, $i$, given by:

$$
c_{t}^{m}=\left(1-\theta_{t}\right)\left[\left(1-\tau n_{t}^{i}-e_{t}^{f, i}\right) w_{t}^{f, i} h_{t}^{f, i}+\left(1-e_{t}^{m, i}\right) w_{t}^{m, i} h_{t}^{m, i}\right]
$$




$$
\begin{aligned}
& c_{t}^{f}=\theta_{t}\left[\left(1-\tau n_{t}^{i}-e_{t}^{f, i}\right) w_{t}^{f, i} h_{t}^{f, i}+\left(1-e_{t}^{m, i}\right) w_{t}^{m, i} h_{t}^{m, i}\right] \\
& e_{t}^{m, i}=\frac{1+\underline{e}^{i}}{2} \\
& e_{t}^{f, i}=\frac{1+\underline{e}^{i}-\tau n_{t}^{i}}{2} \\
& n_{t}^{i}=\frac{\gamma}{\left(1-\theta_{t}\right)} \frac{c_{t}^{m}}{\tau w_{t}^{f, i} h_{t}^{f, i}}
\end{aligned}
$$

The first order conditions illustrate that the consumption levels of the husband and the wife are proportional. Everything else equal that: the trade-off faced by women between the acquisition of own human capital and fertility implies that the optimal number of children is decreasing with the time invested by women in education. Thereby, having more children decreases the time invested in own education for women. In addition, a higher fix cost of education with the acquisition of skilled human capital requires a larger time investment in education.

Optimal Solutions. - The household optimal choices of $c^{f}, c^{m}, n, e^{f}, e^{m}$ conditional to the type human capital acquired is obtained solving the system of equation. We can establish that:

Consumption levels of the husband and the wife are proportional and depend on the bargaining power distribution within the household.

$$
\begin{gathered}
c_{t}^{m *}=\frac{\left(1-\theta_{t}\right)\left(1-\underline{e}^{i}\right)}{(2+\gamma)}\left(w_{t}^{f, i} h_{t}^{f, i}+w_{t}^{m, i} h_{t}^{m, i}\right), \\
c_{t}^{f *}=\frac{\theta_{t}\left(1-\underline{e}^{i}\right)}{(2+\gamma)}\left(w_{t}^{f, i} h_{t}^{f, i}+w_{t}^{m, i} h_{t}^{m, i}\right),
\end{gathered}
$$

The female optimal consumption is increasing with the female marital bargaining power. On the contrary, the male optimal consumption is decreasing with the female bargaining power. Each spouse contributes to a fraction of the household labor earning according to the value of the parameter $\theta_{t}$. In other words, the distribution of the consumption between spouses is function of the level of gender equality within the household. 
At the extreme case $\theta_{t}=0$, for instance, the husband contributes fully to the household labor earnings; there is a strong gender gap between spouses. In the opposite case, since $\theta_{t}=1 / 2$ - there is perfect gender equality, both spouses contribute equitably to the household labor earnings.

Educational optimal choices for both member of the household are given by the following equations:

$$
\begin{aligned}
& e_{t}^{m *}=\frac{1+\underline{e}^{i}}{2} \\
& e_{t}^{f *}=\frac{\left(1+\underline{e}^{i}\right)}{2}-\frac{\gamma\left(1-\underline{e}^{i}\right)}{2 \theta_{t}(2+\gamma)}=e_{t}^{m *}-\frac{\gamma\left(1-\underline{e}^{i}\right)}{2 \theta_{t}(2+\gamma)}
\end{aligned}
$$

Male optimal level of education is function of the fix time cost of education. A higher cost of education in terms of time units requires a larger time investment in education. The optimal female education displays a similar positive impact of the educational cost on the amount of time invested in education. In addition, female optimal education is increasing with the female marital bargaining power. Stronger is the power of the wife within the household, higher is the time she invests in education.

The household optimal fertility is given by:

$$
n_{t}^{i *}=\frac{\gamma\left(1-\underline{e}^{i}\right)}{\tau(2+\gamma)} \frac{\left(w_{t}^{f, i} h_{t}^{f, i}+w_{t}^{m, i} h_{t}^{m, i}\right)}{w_{t}^{f, i} h_{t}^{f, i}} \equiv \frac{\gamma\left(1-\underline{e}^{i}\right)}{\theta_{t} \tau(2+\gamma)}
$$

The inspection of the optimal fertility choice of the household highlights the central role played by the wife within the household decision-making. The optimal fertility is decreasing with the female marital bargaining power. Lower is the bargaining power (male-breadwinner mode) of the wife within the household, higher is the number of offspring. Inversely, higher is the gender equality (dual-earning model), lower is the optimal number of children. Furthermore, we note from the equation (3.20) the existence of a negative relationship between quantity and quality of children. The fix cost of education impacts negatively the optimal number of children. 


\subsubsection{Choice of Human Capital and Fertility}

We consider two types of human capital: the skilled and the unskilled human capital. The choice between each type of human capital depends partly on the level of wages (so as on returns from education, technology). The approach used in what follows shares similarities with Galor and Moav (2002) and Cervellati and Sunde (2007). Substituting $e_{t}^{m, s *}$ and $e_{t}^{m, u *}$; as well as $e_{t}^{f, s *}$ and $e_{t}^{f, u *}$ in the expression of the human capital production function, we obtain the respective male and female levels of human capital:

$$
\begin{aligned}
& h_{t}^{m, i *}(h)=\beta^{i} \frac{\left(1-\underline{e}^{i}\right)}{2} h_{t-1}^{f, i}, \\
& h_{t}^{f, i *}(h)=\beta^{i} \frac{\left(1-\underline{e}^{i}\right)}{2}\left(1-\frac{\gamma}{\theta(2+\gamma)}\right) h_{t-1}^{f, i},
\end{aligned}
$$

For any male and female endowed with parental (maternal) human capital, $h$, there exists unique levels of education $e_{t}^{m, i *}$ and $e_{t}^{f, i *}$, and level of fertility $n_{t}^{i *}$ maximizing their utility, conditional to the type of human capital acquired. Individuals with higher maternal human capital have a comparative advantage in acquiring skilled human capital. Therefore, the amount of individuals endowed with skilled type of human capital increases in $h$. On the contrary, unskilled human capital does not depend on parental human capital. There exist a unique threshold of parental human capital, $\hat{h}_{t}$, such that individuals are indifferent between acquiring skilled or unskilled type of human capital (equalizes their utility).

$$
\hat{h}_{t}=\beta \frac{w_{t}^{u}}{w_{t}^{s}}\left(\frac{1-\underline{e}^{u}}{1-\underline{e}^{s}}\right)^{2+\gamma}
$$

For a given distribution of parental human capital $d(h),{ }^{16}$ the threshold $\hat{h}$ determines the fraction of individuals that choose to acquire skilled human capital. This threshold is a monotonically increasing function of the relative wage between unskilled and skilled human capital, $\left(w_{t}^{u} / w_{t}^{S}\right)$.

$$
\left(1-\Lambda_{t}\right)=\int_{0}^{\hat{h}} d(h) d h=\hat{h} \text { and } \Lambda_{t}=\int_{\hat{h}}^{1} d(h) d h=(1-\hat{h})
$$

${ }^{16} d(h)$ denotes the distribution of "cultural capital" within a given generation of new individuals. 
Thereby, all agents with $h>\widehat{h}$ acquire skilled human capital (a fraction $\Lambda_{t}$ of the population) while all agents with $h<\widehat{h}$ acquire unskilled human capital (a fraction $1-\Lambda_{t}$ of the population). Higher is the skilled wage, lower is the relative wage and bigger is the fraction of people acquiring skilled human capital. For any level of parental human capital there is a unique optimal level of education and level of fertility which maximize the utility function. According to equation (3.29) and (3.30), the acquisition of skilled rather than unskilled human capital induces individuals to spend more time on education $\left(e_{t}^{S *}>e_{t}^{u *}\right)$ and to have a lower number of children $\left(n_{t}^{S *}<n_{t}^{u *}\right)$. The difference of fertility obtained according to the type of education is one of the most (if not the most) fundamental ingredient in the model.

The maternal human capital is conditional to education and fertility choices which depend on cultural and technological environment. One of the key determinants of educational investments is the rate of technological progress. Through this channel, the rate of technological change affects gender roles by increasing female marital bargaining power (what drives to higher equality between men and women).

Choices of human capital type and optimal fertility are function of the time spent by individuals in education. The acquisition of skilled rather than unskilled human capital induces individuals to spend more time on skilled education and to have a lower number of children. Inversely, individuals choosing to invest in unskilled education have a higher number of children. Differential fertility emerges since the acquisition of skilled human capital induces girls to substitute utility from number of children with utility from consumption. Ultimately, this mechanism drives to a fertility transition.

The threshold level of parental human capital making an individual indifferent between acquiring skilled or unskilled human capital, $\widehat{h}_{t}$, is decreasing in gender equality $\theta$. It induces a larger share of the population to optimally acquire formal education $\Lambda_{t}$. Any change in the fraction of individuals acquiring skilled and unskilled human capital (skill composition of the population, $\Lambda_{t}$ ) impacts the average fertility of the population. For any $\left\{A_{t}, \theta_{t}, g_{t}\right\}$, the average fertility is given by the following equation:

$$
n_{t}^{i *}=\left(1-\Lambda_{t}\right) n_{t}^{u}+\Lambda_{t} n_{t}^{S} \equiv \frac{\gamma}{(2+\gamma)} \frac{\left(1-\underline{e}^{u}\left(1-\Lambda_{t}\right)-\Lambda_{t} \underline{e}^{s}\right)}{\tau \theta_{t}}
$$

with $\frac{\partial n_{t}^{*}}{\partial \theta_{t}}<0$. 
Gender equality is a key determinant of the average fertility. The fertility rate is negatively correlated with the level of gender equality within the population. Improvements in $\theta$ induce more people to acquire education (especially girls). Henceforth, improvements in gender equality induce a generalized decline in fertility. An economy with lower gender equality is characterized by lower fertility rate. Gender equality in the form of female marital bargaining power affects fertility by inducing a change in the female optimal choice of education time and in the type of education. Finally, an increase in female human capital is associated with reduction of the number of children and an increase in their quality. Associated together, the different effects of technological progress and gender equality can account for the demographic and the economic transition, such that fertility decreases, education expands and growth reaches a sustained level.

\subsection{Distribution of Labor Types}

The aggregate levels of each type of human capital are given by:

$$
\begin{aligned}
& L_{t}^{u}=H_{t}^{u}(\hat{h})=N_{t} \int_{0}^{\hat{h}} h_{t}^{u}(\hat{h}) d(h) d h, \\
& L_{t}^{s}=H_{t}^{s}(\hat{h})=N_{t} \int_{\hat{h}}^{1} h_{t}^{s}(\hat{h}) d(h) d h,
\end{aligned}
$$

There exists a unique threshold of "cultural capital" (derived from maternal endowment in human capital) that splits the population between individuals acquiring skilled and unskilled human capital. From (2) and (3), we determine the unskilled-to-skilled wage rates on competitive markets.

$$
\frac{w_{t}^{u}}{w_{t}^{s}}=\frac{1-\alpha_{t}}{\alpha_{t}}\left(\frac{L_{t}^{u}}{L_{t}^{s}}\right)^{\rho-1}
$$

The wage rates ratio depends itself on the ratio of the aggregate level of unskilled and skilled human capital. 


\section{The Dynamic Evolution of the Economy}

\subsection{Dynamic Evolution of the Key Variables}

The evolution of the economy is characterized by demographic and economic transitions. In particular, the development of the economy is characterized by the evolution of educated people, technological level and gender equality. The global dynamics of the economy is described by the trajectory of gender equality $\theta_{t}$, the share of the population acquiring skilled human capital $\Lambda_{t}$ and the total factor productivity. We can study the dynamic development of the economic by analyzing the evolution of the key state variables over generations. The evolution of the economy is fully described by a sequence $\left\{\Lambda_{t}, \theta_{t}, \alpha_{t}\right\}_{t=0}^{\infty}$, resulting from the evolution of the three-dimensional nonlinear first-order system.

\subsubsection{The Fraction of Skilled Individuals}

The equilibrium fraction of the population acquiring human capital is monotonically increasing in $\theta_{t}$. The higher the gender equality, the more people invest in the acquisition of skilled human capital. Intuitively, for low levels of gender equality the fraction of skilled individuals is small. There is no accumulation of human capital and the returns from investing in skilled education do not worth the effort. Very large improvements in gender equality are necessary to make individual invest in skilled education and then to allow for human capital accumulation. The equilibrium fraction of the population acquiring human capital also depends on the technological environment - is increasing in the relative productivity of skilled human capital intensive sector, $\alpha_{t}$. The labor market condition equilibrium is given by:

$$
\Lambda_{t}=\Lambda\left(\theta_{t}, \alpha_{t}\right),
$$

which is an increasing and S-shaped function of $\theta_{t}$.

\subsubsection{Dynamic Evolution of Gender Equality}

Based on historical evidence, we suggest that gender equality is function of the stock of skilled human capital of spouses (measuring human capital on the bargaining power distribution), such that 
gender equality increases with individuals human capital. In particular, gender equality is linked with the distribution of knowledge embodied in individuals in the previous generation, $t-1$ (function of the average stock of female skilled human capital), through the time invested in skilled education $\left(e_{t-1}^{S}\right)$. The dynamic evolution of gender equality can be expressed as:

$$
\theta_{t}=\theta\left(\theta_{t-1}, \Lambda_{t-1}\right)
$$

This expression involves that gender equality is increasing with the share of individuals (within the parental generation) acquiring skilled human capital.

\subsubsection{Process of Technological Process}

The process of technological change depends on the stock of skilled human capital (biased toward skill-intensive sector of production). The available stock of human capital in a generation $t$ makes human capital more profitable to acquire for future generations. The dynamic evolution of technological progress is given by:

$$
g_{t}=\boldsymbol{G}\left(\Lambda_{t-1}, A_{t-1}\right)
$$

which implies that the productivity $A_{t}$ increases with the aggregate level of skilled human capital of a generation using the previous technology available in the economy. This level of technology is then function of the fraction of skilled people in the parent generation, as well as the level of productivity achieved in $t-1$.

\subsection{The Dynamical System}

In order to characterize the dynamic development of the economy, we study the trajectory of three key variables over generations. The path of the economy is entirely described by the sequence $\left\{\Lambda_{t}, \theta_{t}, \alpha_{t}\right\}_{t=0}^{\infty}$, according to the evolution of the nonlinear first-order dynamic system of equations:

$$
\left\{\begin{array}{l}
\Lambda_{t}=\Lambda\left(\theta_{t}, \alpha_{t}\right) \\
\theta_{t}=\theta\left(\theta_{t-1}, \Lambda_{t-1}\right) \\
g_{t}=\boldsymbol{G}\left(\Lambda_{t-1}, \alpha_{t-1}\right)
\end{array}\right.
$$


The dynamic path of $\Lambda, \theta$ and $\alpha$ describes the joint evolution of the share of individual acquiring skilled education, gender equality and the relative productivity share (of each type of labor), given initial conditions $\Lambda_{0}, \theta_{0}$ and $\alpha_{0}$. The dynamic path does not depend on population size (no scale effect). We focus on the sub-system of equations, conditional on the value of the productivity share, $\alpha_{t}$, in order to illustrate the development dynamics. It results from the labor market equilibrium and the intergenerational externality on gender equality:

$$
\left\{\begin{array}{l}
\Lambda_{t}=\Lambda\left(\theta_{t}, \alpha_{t}\right) \\
\theta_{t}=\theta\left(\theta_{t-1}, \Lambda_{t-1}\right)
\end{array}\right.
$$

The system delivers the dynamics of human capital formation and gender equality for a given relative productivity share $\alpha>0$. Any steady-state of the sub-system of equation is characterized by the intersection of $\boldsymbol{\Lambda}$ and $\theta$.

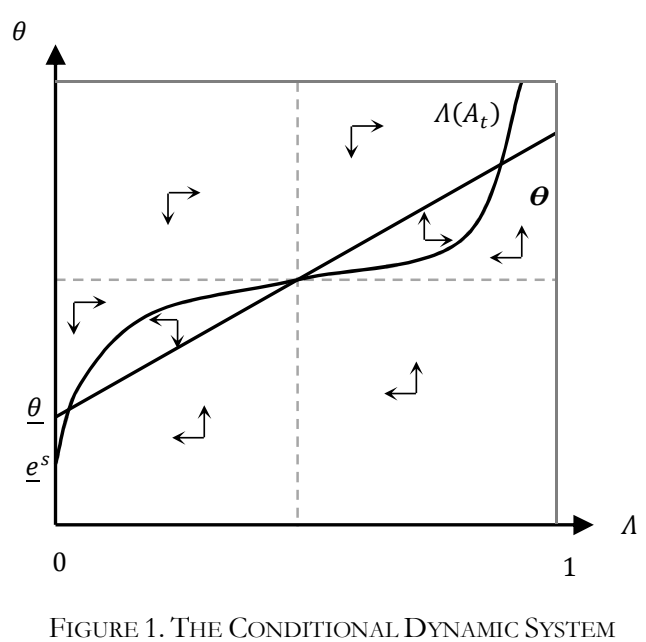

Given the non-linearity of $\boldsymbol{\Lambda}$ (S-shape trajectory), the dynamic sub-system is characterized by three different configurations that exhibit from one to three steady-state equilibria (see Figure 1 for the latter case). There are two stable and one unstable steady-state. The low steady state equilibrium is characterized by low gender equality and a small share of population acquiring skilled human capital. On the opposite, the high steady-state equilibrium is characterized by high gender equality and a relatively large fraction of population acquiring skilled human capital. Figure... illustrates the system under the existence of three steady-state equilibria. The state of the value of the productivity affects 
the relative returns from skilled human capital. A higher productivity, $A$, increases the returns to skilled human capital and the associated equilibrium fraction of individuals, $\Lambda$.

\subsection{The Global Dynamics of Development}

The evolution of the economy has to account for the evolution of all state variables. We focus here on the entire path of development: from stagnation to sustained growth. Then, how can economies move from the Malthusian trap of stagnation (with high fertility) to an era of sustained growth (with low fertility)?

We emphasize the existence of three main stages of development: the early stage of development ("Non-developed economy"), the transitory stage - toward the development ("Transitory economy") and the final stage of development (“Developed economy").

\subsubsection{Non-Developed Economy}

Non-developed economies are characterized by low gender equality $\underline{\theta}$ (close to its minimum) and low value of productivity $A_{0}$ (initial level). According to these conditions, investing in skilled human capital is costly for a large majority of the population. Thereby, the fraction of individuals acquiring skilled human capital $\Lambda$ is very low. The corresponding average fertility reflects those of individuals acquiring unskilled human capital (high fertility).

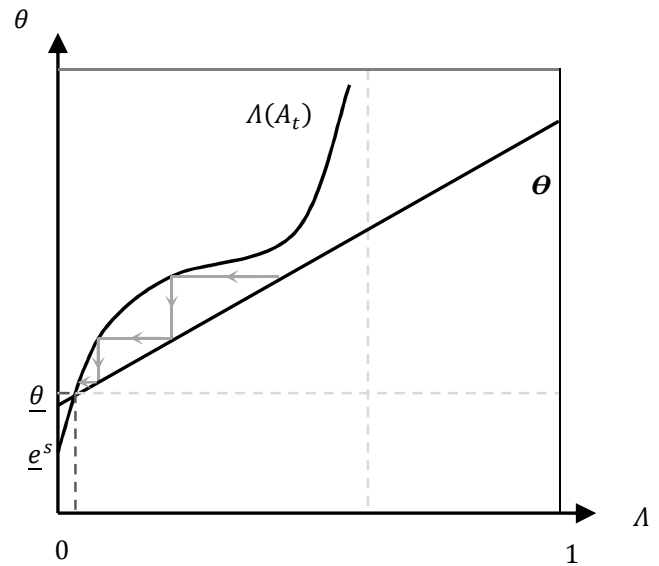

Figure 2. The Early Stage of the Process of Development 
Graphically, every intersection of the locus $\boldsymbol{\theta}$ and $\boldsymbol{\Lambda}$ represents an equilibrium. With initial low level of gender equality and low changes in technological progress, the dynamic system exhibits a unique globally stable steady-state equilibrium.

In a non-developed economy, gender equality and technological progress are close to their minimum, $\theta_{0} \simeq \underline{\theta}$ and $A_{0} \simeq 0$. The conditional system exhibits a unique steady state with few individuals acquiring skilled human capital $h^{s}, \Lambda_{0} \simeq 0$, and with large fertility rates.

$$
n \simeq \frac{\gamma}{\underline{\theta}(2+\gamma)} \frac{\left(1-e^{u}\right)}{\tau}
$$

At this stage of development, the economy is characterized by an extended phase with low living standards, low gender equality and large fertility.

\subsubsection{Transitory Economy}

As emphasized previously, Western countries experienced both an economic and a demographic transition. This transition account for a switchover from an environment characterized by low income per capita, low investments in education and high fertility to economy characterized by high living standards, a high share of the population investing in education and low number of children per women. Endogenous skill biased technological change leads to a monotonic increase in the importance of skilled human capital for production (by reinforcing the adoption of new ideas and technologies). Therefore, as generations pass, productivity growth makes investing in skilled education more profitable. However, as long as a certain level of gender equality is not reached, the process of human capital accumulation cannot start.

Graphically, productivity growth increases the convex part of the curve $\boldsymbol{\Lambda}$. The dynamic equilibrium moves along $\theta$ triggering improvements in gender equality. Fertility remains high since the fraction of skilled individual is low. $\boldsymbol{\Lambda}$ slowly shifts downwards and after sufficiently many generations $\boldsymbol{\Lambda}$ exhibits three intersections with $\theta$, that are multiple equilibria: two locally stable steady-states and an interior unstable steady-state. In the absence of large shocks, the economy remains at the low steady-state equilibrium. 


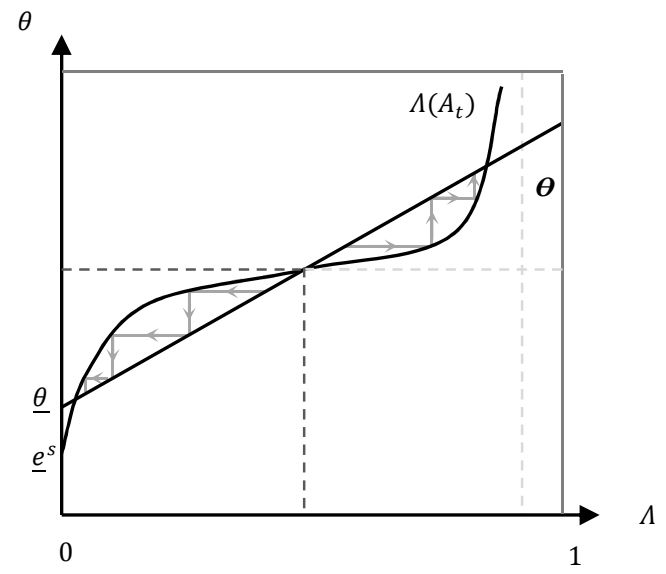

Figure 3. The Transitory Stage of the Process of Development

During this stage of development, the economy experiences increases in $\theta_{t}, \Lambda_{t}$, income per capita $\left(y_{t}\right)$ and technological level $A_{t}$. At this transitory stage of development, the economy is characterized by improvements in living standards, low gender equality and large fertility.

\subsubsection{Developed Economy}

In contrast to early stages of development, mature stages of development are characterized by advanced technology and high living standard. Gender equality is high, close to its maximum $\bar{\theta}$. Given these characteristics, investing in skilled human capital is much cheaper than in less advanced economy. As a consequence, the very large majority of the population acquires skilled human capital. Thereby, the fraction of individuals acquiring skilled human capital $\Lambda$ is very high. The corresponding average fertility reflects those of individuals acquiring unskilled human capital (low fertility).

In other words, the reach of a specific threshold in gender empowerment engages the process of human capital accumulation. Due to larger educational investments (in terms of time units), the female opportunity cost of having children increases and average fertility declines. Accordingly, households have fewer children but each of them is endowed with a higher quality of parental human capital - what de facto increases the ability of children to succeed in education and allow them to become in turn skilled individuals. From generations to generations, the fraction of skilled individuals increases and generates a positive feedback loop, impacting positively the rate of 
technological progress and the value of productivity. Ultimately, the economy experiences both a demographic and economic transition driven by improvements in gender equality.

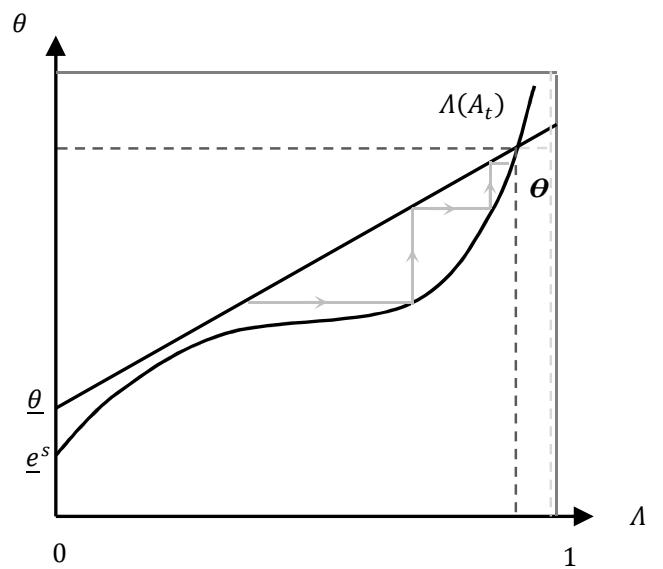

Figure 4. The Late Stage of The Process of Development

Graphically, as $\boldsymbol{\theta}$ and $\boldsymbol{\Lambda}$ shift downwards, the dynamic equilibrium exhibits a unique globally stable steady-state (a single intersection between the two curves). Once gender equality growth to a high level, $\bar{\theta}$, a substantially large fraction of the population decide to acquire skilled human capital. Therefore, it triggers to a period of rapid development (transition in living conditions) and the economy converges to the globally stable steady-state.

In a developed economy, with $A_{0} \simeq 1$, the conditional system exhibits a unique steady state where almost all the population acquire skilled human capital, $\Lambda \simeq 1$; gender equality is high $\theta \simeq \bar{\theta}$ and fertility rates are low,

$$
n \simeq \frac{\gamma}{\bar{\theta}(2+\gamma)} \frac{\left(1-e^{s}\right)}{\tau}
$$

At this mature stage of development, the economy is characterized by an extended phase with high living standards, high gender equality and low fertility.

The development process is therefore characterized by the evolution of economies from an era of stagnation to the demographic transition and the Modern Growth through the post-Malthusian Regime (such as in Galor and Moav, 2002). Our model provides a new approach (complementary to existing unified models, and notably those of Galor) with new mechanisms and new answers on how economies managed to escape the Malthusian trap to reach a state of sustained growth and to 
experience a demographic transition. In our model, the prime driving forces in this transition emerge from gender empowerment, as depicted by the phase diagrams (Figure 2 to 4 ).

The rise in the rate of technological progress (through the emergence of new technologies) during the process of industrialization increased the demand for human capital and together raised the level of gender equality. Gender empowerment induces changes in gender relations. This gave greater opportunities for women to have access to higher education. Therefore, investing in education increases the opportunity cost of having children and implies for women to face a trade-off between education and fertility (professional versus family sphere). This is the so-called quantity-quality tradeoff. ${ }^{17}$ This process ultimately triggers to the demographic transition.

\section{Conclusion}

This chapter shed lights on the importance of the role played by female empowerment and family organization on the development process. We argue that gender empowerment have been necessary to allow economies to move from stagnation to sustained growth. Our intuition is that the transition from a "Patriarchal" organization of the society (male-breadwinner model), characterized by a sexual division of labor with a desire for households to maximize both their income and the number of children, toward a "Modern" organization of the society (dual-earnings model), characterized by a better distribution of duties within the household, where both men and women work on the labor market, is at the heart of both the process of human capital accumulation and the demographic transition that occurred during the process of development in Western countries.

More specifically, we develop a unified cliometric growth model that encompasses the interplay between income, gender equality and fertility. Our model suggests that gender empowerment is a crucial factor of both demographic and economic transition. In particular, the theory points out that the acceleration of skill-biased technological progress generates a positive externality on the level of gender equality. Both wages and gender equality are key variables in the education decision process of individuals. More specifically, higher gender equality reinforces individuals' incentives to acquire skilled human capital. In turn, female choices in terms of time and quality of educational investments increase their endowment in human capital and impact positively the fraction of the subsequent generation of individuals acquiring skilled education. In other words, improvements in technological

17 Becker (1960) was the first to introduce the distinction between child quantity and child quality, followed by Becker and Lewis (1973) and Willis (1973). 
progress, gender equality and skilled human capital reinforce each other. Ultimately, the presence of a sufficiently high fraction of skilled individuals in the population yields to sustained economic growth.

In the early stage of development, the low rate of technological progress does not provide any incentive to invest in skilled education. Therefore, the fraction of skilled individuals is low and the economy remains trapped in Malthusian steady-state equilibrium, with low education, low living standard and low gender equality. Technological progress is assumed to increase monotonically from generation to generation. Thereby, as technological progress grows, we observe a qualitative change, and the subsequent income effect triggers (temporarily) to higher fertility rates. After sufficiently many generations, increases in the returns from investments in skilled education (productivity growth) - driven by the rise in technological progress - makes investing in skilled education more profitable so that gender equality improves. The dynamical system of skilled human capital and gender equality is therefore characterized by multiple steady-state equilibria. Since gender equality becomes high enough, a substantially larger fraction of individuals acquires skilled human capital what triggers to rapid developments and reinforces gender equality. Due to larger educational investments (in terms of time units), female opportunity cost of having children increases and average fertility declines: the demographic transition occurs along with the process of human capital accumulation. Ultimately, in later stage of development, gender equality and the fraction of skilled individuals converge towards their maximum. Thereby, the economy is characterized by Modern Growth steady-state equilibrium, where living standards are high, gender equality is high and fertility is low.

Hence, through the construction of a unified growth model, this chapter emphasizes the importance of considering gender empowerment and family organization as a key ingredient of the development process. In particular, it highlights the mechanisms through which it contributed to engage the transition from stagnation to sustained economic growth. 


\section{REFERENCES}

Barro R.J., G.S. Becker (1989), "Fertility Choice in a Model of Economic Growth". Econometrica, 57, p. 481-501.

Becker G.S. (1960), “An Economic Analysis of Fertility”, In: Gary S. Becker (ed.), Demographic and Economic Change in Developed Countries, p. 209-240. Princeton, NJ: Princeton University Press.

Becker G.S. (1965), “A Theory of the Allocation of Time”, Economic Journal, 75, p. 493-517.

Becker G.S. (1981), A Treatise on the Family. Cambridge, MA: Harvard University Press.

Becker G.S., H.G. Lewis (1973), "On the Interaction between the Quantity and Quality of Children", Journal of Political Economy, 81, p. 279-288.

Becker G.S., K.M. Murphy, R. Tamura (1990), "Human Capital, Fertility, and Economic Growth”, Journal of Political Economy, 98, p. 12-37.

Becker S.O., F. Cinnirella, L. Woessmann (2012), “The Effect of Investment in Children's Education on Fertility in 1816 Prussia", Cliometrica, 6, p. 29-44.

Cervellati M., U. Sunde (2005), "Human Capital Formation, Life Expectancy and the Process of Development", American Economic Review, 95, p. 1653-1672.

Cervellati M., U. Sunde (2007), "Human Capital Formation, Mortality and Fertility: A Unified Theory of the Economic and Demographic Transition", IZA Discussion Paper, No 2905, July.

Cuberes D., M. Teignier-Baqué (2012), "Gender Inequality and Economic Growth", World Development Report 2012: Gender Equality and Development, Background paper.

Currie J., E. Moretti (2003), “Mother's Education and the Intergenerational Transmission of Human Capital; Evidence from College Openings", Quarterly Journal of Economics, 118, p. 1495-1532.

Dahan M., D. Tsiddon (1998), "Demographic transition, income distribution, and economic growth", Journal of Economic Growth, 3, p. 29-52.

De La Croix D., M. Vander Donckt (2010), "Would Empowering Women Initiate the Demographic Transition in Least-Developed Countries?", Journal of Human Capital, 4, p. 85-129.

Doepke M., M. Tertilt (2009), "Women's Liberation: What's in it for men", Quarterly Journal of Economics, 124, p. 1541-1591.

Ehrlich I., F.T. Lui (1991), "Inter-generational Trade, Longevity, and Economic Ggrowth”, Journal of Political Economy, 99, p. 1129-1059. 
Galor O. (2005), "From Stagnation to Growth: Unified Growth Theory”, In: Aghion P., Aghion, S.N. Durlauf (eds.), Handbook of Economic Growth, Vol. 1A, p. 171-293. Amsterdam: North Holland.

Galor O. (2011), Unified Growth Theory, Princeton University Press.

Galor O. (2012), “The Demographic Transition: Causes and Consequences”, Cliometrica, 6, p. 494504.

Galor O., O. Moav (2002), "Natural Selection and the Origin of Economic Growth", Quarterly Journal of Economics, 117, p. 1133-1191.

Galor O., D.N. Weil (1996), “The Gender Gap, Fertility, and Growth”, American Economic Review, 86, p. 374-387.

Galor O., D.N. Weil (1999), "From Malthusian Stagnation to Modern Growth". American Economic Review, 89, p. 150-154.

Galor O., D.N. Weil (2000), "Population, Technology, and Growth: From Malthusian Stagnation to the Demographic Transition and Beyond", American Economic Review, 90, p. 806-828.

Goldin C. (2006), “The Quiet Revolution that Transformed Women's Employment, Education, and Family", National Bureau of Economic Research, Working Paper No. 11953, January.

Iyigun M.F. (2000), "Timing of Childbearing and Economic Growth", Journal of Development Economics, 61, p. 255-269.

Iyigun M.F., R.P. Walsh (2007), "Endogenous Gender Power, Household Labor Supply and the Demographic Transition", Journal of Development Economics, 82, p. 138-155.

Klemp M. (2012), "Price, Wages and Fertility in Pre-Industrial England", Cliometrica, 6, p. 63-78.

Lagerlöf N.P. (2003), “Gender Equality and Long-Run Growth”, Journal of Economic Growth, 8, p. 403-426.

Lucas R.E. (1988), “On the Mechanics of Economic Development". Journal of Monetary Economics, 22, p. 3-42.

Malthus R.T. (1798), Essai sur le principe de population. Traduction de E. Vilquin, 1980, INED et PUF, Paris.

Mincer, J. (1962), Labor Force Participation of Married Women: A Study of Labor Supply. Aspects of labor economics, H. Gregg Lewis (eds). Princeton: Princeton University Press, p. 63-97.

Nerlove, M. (1974), "Toward a New Theory of Population and Economic Growth", Journal of Political Economy, 84, p. 200-216. 
Razin A., U. Ben-Zion (1975), "An Intergenerational Model of Population Growth", American Economic Review, 65, p. 923-933.

Romer P. (1986), "Increasing Returns and Long-run Growth", Journal of Political Economy, 94, p. 1002-1037.

Romer P. (1990), "Endogenous Technological Change", The Journal of Political Economy, 98, p. S71S102.

Schultz T.P. (1995), "Investments in Schooling and Health of Women and Men: Quantities and Returns”, In: Schultz T.P. (ed.), Investment in Women's Human Capital. Chicago: University of Chicago Press.

Soares, R. R., B. L. Falcao (2008), "The demographic transition and the sexual division of labor", Journal of Political Economy, 116(6), p. 1058-1104.

Solow R.M. (1956), "A Contribution to the Theory of Economic Growth", Quarterly Journal of Economics, 70, p. 65-94.

Srinivasan T.N. (1988), "Population Growth and Economic Development", Journal of Policy Modeling, 10, p. 7-28.

Tamura R. (1994), "Fertility, Human Capital and the Wealth of Families", Economic Theory, 4, p. 593603.

Willis R.J. (1973), “A New Approach to the Economic Theory of Fertility Behavior", Journal of Political Economy, 81, p. 14-64. 